\section{Desafios da nutrição no Sistema Único de Saúde para construção da interface entre a saúde e a segurança alimentar e nutricional}

\author{
Nutritional challenges in the Brazilian Unified \\ National Health System for building the interface \\ between health and food and nutritional security \\ Desafíos de la nutrición en el Sistema Único de \\ Salud brasileño para la construcción de la interfaz \\ entre la salud y seguridad alimentaria y nutricional
}

Silvia do Amaral Rigon 1

Suely Teresinha Schmidt 2

Cláudia Maria Bógus ${ }^{3}$

\title{
Resumo
}

Discute-se a construção da intersetorialidade entre o campo da saúde e da segurança alimentar e nutricional (SAN) no Brasil, entre 2003 e 2010, período que inaugura a priorização deste tema na agenda governamental. Para tanto, desenvolveu-se uma pesquisa qualitativa segundo a epistemologia construcionista, mediante entrevistas com informantes-chave do órgão de controle social do campo da SAN de abrangência nacional. Os avanços e desafios do processo são abordados enquanto categorias de análise. A Política Nacional de Alimentação e Nutrição (PNAN) foi mencionada como articuladora entre os dois campos, sendo descentralizada por uma rede com atuação nos estados e municípios. No entanto, registraram-se dificuldades politicas, institucionais e operacionais para que a PNAN possa ser efetiva no Sistema Único de Saúde e assim contribuir para o avanço da SAN no país. O predomínio do modelo biomédico, curativo e de alta complexidade foi referido como o principal impeditivo, conferindo ainda às políticas de promoção da saúde, como a PNAN, uma posição secundária em termos da sua priorização.

Segurança Alimentar e Nutricional; Políticas Públicas; Nutrição em Saúde Pública; Alimentação

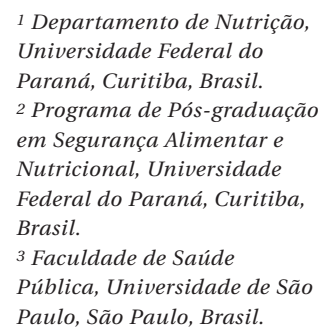

Correspondência S. A. Rigon Departamento de Nutrição, Universidade Federal do Paraná.

Rua Lothário Meissner 632, Curitiba, $P R$ 80210-170, Brasil. silviarigon@gmail.com 
A construção da intersetorialidade no âmbito da saúde ainda constitui uma necessidade premente, pois apesar de ser evidente o peso das questões sociais, econômicas, culturais e ambientais na determinação da saúde, do adoecimento e do cuidado, persistem dificuldades para obtenção da transversalidade de ações necessárias à promoção da saúde, temática que consiste em referencial fundamental da reforma sanitária brasileira 1,2 .

O presente artigo tem por objetivo discutir os desafios da construção de uma articulação intersetorial entre a área da saúde e a da segurança alimentar e nutricional (SAN), considerando a nutrição como área estratégica para esta interface. Tal articulação institui-se quando "setores pactuam um projeto integrado, identificam determinantes-chave do problema em pauta, formulam intervenções estratégicas que transcendem os programas setoriais e alocam recursos em função dessas prioridades" 3 (p. 853).

Entende-se que o campo da SAN está em construção no Brasil 4,5 e que tem como conceito de referência "a realização do direito de todos ao acesso regular e permanente a alimentos de qualidade, em quantidade suficiente, sem comprometer o acesso a outras necessidades essenciais, tendo como base práticas alimentares promotoras de saúde, que respeitem a diversidade cultural e que sejam social, econômica e ambientalmente sustentáveis" ${ }^{6}$. Tal conceito, pautado no marco legal que instituiu o Sistema Nacional de SegurançaAlimentar e Nutricional (SISAN) no Brasil, em 2006, é um objetivo de política pública resultante de uma construção histórica, que envolveu a mobilização de diversos segmentos da sociedade civil oriundos dos movimentos sociais, da academia e do setor técnico 7. Para a sua consolidação, necessita de uma atuação governamental integrada e intersetorial, mediante a consecução da Política Nacional de Segurança Alimentar e Nutricional (PNSAN). Tal política, sancionada em 2010 , vem sendo implementada no país pela Câmara Interministerial de SAN (CAISAN), com o auxílio do desenvolvimento do Plano Nacional de Segurança Alimentar e Nutricional (PLANSAN) 9 e com o monitoramento do Conselho Nacional de Segurança Alimentar e Nutricional (CONSEA) 7. O fortalecimento das ações de alimentação e nutrição em todos os níveis da atenção à saúde, de modo articulado às demais políticas de segurança alimentar e nutricional, consiste em uma de suas diretrizes 9 .

Apesar dos avanços realizados no país nesse campo ${ }^{10}$, pesquisa publicada em $2014{ }^{11}$ verificou que $22,6 \%$ das famílias brasileiras ainda vivem em graus diferenciados de insegurança alimentar: 14,8\% em situação de insegurança ali- mentar leve, 4,6\% em situação moderada e 3,2\% em situação grave. Tal quadro, revelador de um processo histórico, é retrato da convivência da desigualdade social e de condições precárias de vida, inseridas num sistema agroalimentar que promove a artificialização da alimentação e a mercadorização dos alimentos. Constitui uma forma de expressão de processos mais abrangentes que interferem no organismo biológico, manifestando-se pela desnutrição, doenças carenciais, sobrepeso e obesidade, que afetam negativamente o estado de saúde e a qualidade de vida da população ${ }^{12,13}$.

Concebida para atuar na direção contrária a essa tendência, a política de SAN constitui um conjunto de ações planejadas para garantir a produção e o acesso aos alimentos para toda a população promovendo a nutrição e a saúde. Trata-se de uma política que é realizada em diferentes esferas (produção, distribuição, comercialização, acesso e consumo dos alimentos), necessitando para a sua concretização do envolvimento das áreas de agricultura, abastecimento, trabalho, economia, saúde, educação, meio ambiente, proteção e promoção social, dentre outras. É uma política que deve implementar ações abrangentes e de caráter estruturante que transformem o processo de determinação social da insegurança alimentar e nutricional, articulando-as com medidas de curto e médio prazos que garantam de forma urgente o enfrentamento da pobreza, da fome e da alimentação de má qualidade 12 .

Para alcançar os seus objetivos, a política de SAN requer priorização na agenda governamental, decisão política e participação ativa da sociedade civil no seu processo de concepção, implementação e monitoramento 7 .

Assim, considerando os objetivos da política de SAN, é possível compreender como a mobilização que vem ocorrendo no Brasil nos últimos anos com vistas à implementação do SISAN e PNSAN pode ser entendida como estratégica para a efetivação da promoção da saúde 14,15. Da mesma forma, a participação do setor saúde na construção desse processo de implementação do sistema e da política nacional consiste também em uma questão essencial e indispensável à consolidação da SAN no país.

\section{Metodologia}

O estudo baseou-se no referencial teórico-metodológico da epistemologia construcionista, que considera a produção do conhecimento como uma construção social, que se realiza com base nos significados e representações que os 
indivíduos elaboram em relação ao contexto no qual estão inseridos e segundo as experiências que nele vivenciam 16,17 .

As informações para atender o objetivo da pesquisa foram obtidas mediante investigação de abordagem qualitativa com integrantes do CONSEA, órgão responsável pelo controle social da política de SAN. Para a composição do grupo participante da pesquisa, foram identificados sujeitos com trajetórias históricas no campo da SAN, que tivessem condições de contribuir na construção do objeto de estudo em sua totalidade, considerando as suas várias dimensões 18 .

Na seleção dos informantes-chave foi mantida a proporcionalidade observada no CONSEA, ou seja, 2/3 dos entrevistados oriundos da sociedade civil e 1/3 do governo. As áreas de atuação e de inserção institucional dos entrevistados foram: agricultura, saúde, assistência social, mobilização social e segurança alimentar e nutricional. Dentre os participantes do estudo, sete são do sexo feminino e três do masculino. A faixa etária predominante ficou entre 40 e 55 anos. O número total de integrantes do estudo foi definido a partir do momento em que se atingiu o ponto de saturação em relação aos conteúdos obtidos, tendo sido necessária a efetivação de dez entrevistas 18 .

As entrevistas em profundidade foram pautadas em um roteiro dividido em três partes: a primeira abordou a concepção de SAN e o processo histórico de sua construção no Brasil; a segunda enfocou questões relativas à área de Nutrição inserida na grande área da saúde; e a terceira parte foi referente à construção da intersetorialidade entre a saúde e a SAN. As entrevistas foram gravadas e transcritas, sendo o seu conteúdo sistematizado, categorizado e analisado para responder às perguntas do roteiro mencionado. $\mathrm{O}$ método foi a análise de conteúdo 18,19.

O recorte temporal do estudo foi de 2003 a 2010. Tal período corresponde à recente inserção da SAN como prioridade na agenda do governo brasileiro e o início da institucionalização de suas políticas, correspondendo a dois mandatos presidenciais. É somente no final de 2010 que ocorre a criação da PNSAN. Por conta disso, o estudo considera a SAN enquanto campo de ação e não como política já instituída.

Destacaram-se como temas os avanços e as dificuldades relativos à participação do setor saúde na construção da SAN, tendo a área da Nutrição como interface, no contexto do Sistema Único de Saúde (SUS). Baseando-se na identificação dessas duas categorias temáticas buscouse realizar uma discussão crítica das questões emergentes, em diálogo com referenciais teóricos selecionados, identificando-se os principais desafios para a construção da intersetorialidade entre a saúde e a SAN.

Este artigo consiste em um recorte de uma tese de doutorado 20 , cujo desenvolvimento foi aprovado pelo Comitê de Ética em Pesquisa da Faculdade de Saúde Pública, Universidade de São Paulo (575.0.000.207-09/FR - 245715).

\section{Resultados}

Em relação ao processo de construção da SAN, os entrevistados fazem um resgate de processos políticos que ocorreram no Brasil nas décadas de 1980 e 1990. As falas assinalam a contribuição de dois campos do saber como disseminadores das ideias que fundamentaram tal dinâmica:

"O processo de construção, eu vejo como resultado de dois campos de saber e de articulação que se uniram. Um campo que vem do lado das ciências sociais e agronômicas, ligadas ao tema da agricultura e do meio rural, e o outro campo que vem da saúde, ligado justamente a esses temas de nutrição; esses dois campos se encontraram no final dos anos 80 e início dos anos 90, e a partir daí foi se dando uma construção para a qual contribuíram pesquisadores, militantes, movimentos e organizações e gestores públicos de ambos os campos, apontando para essa construção" (Entrevistado no 02, sociedade civil, grifos nossos).

“...em 1986, na primeira Conferência Nacional de Alimentação e Nutrição, a gente está há 24 anos, esse eu acho que é um marco interessante... $\mathrm{E}$ aí o pessoal da saúde foi ator fundamental, trazer isso para esse debate institucionalizado, organizado e tal, com conferências, já propondo uma política nacional, o sistema nacional, isso já sai daquele momento..." (Entrevistado no 08 , governo, grifos nossos).

Os entrevistados destacam a contribuição do setor saúde no processo de construção nacional da SAN, registrando a realização da Conferência Nacional de Alimentação e Nutrição, em 1986, como um marco de discussão das principais ideias e propostas para a área. Após um longo processo de mobilização da sociedade civil e de técnicos da área, tais concepções constituíram-se em uma das bases do SISAN, criado em 2006, com o marco da Lei Orgânica de Segurança Alimentar e Nutricional (LOSAN).

Nesse resgate histórico a Política Nacional de Alimentação e Nutrição (PNAN) 21 foi destacada pelos entrevistados como uma política fundamental para a construção da SAN no país. A criação da PNAN, em 1999, possibilitou as discussões da área de alimentação e nutrição voltadas à SAN, num momento da história do país em 
que não havia intenção, por parte do governo, em implantar uma política federal nessa área 22. Segundo os entrevistados, ao longo de seus dez anos de implementação a PNAN desenvolveu ações fundamentais para a construção da SAN com base na saúde:

“...Ela teve algumas visualizações que o próprio movimento de SAN não tinha, que é a questão do direito humano. Então $a$ PNAN é uma política à frente do seu tempo... E quando ela é promulgada em 1999, toma para si a responsabilidade de coordenar a intersetorialidade, olhando $a$ segurança alimentar e nutricional, que naquele momento não tinha eco dentro do Estado brasileiro, então ela tomou para si essa responsabilidade; ela traz um conceito ainda não completamente compreendido no Brasil e no mundo..." (Entrevistado no 10, sociedade civil, grifos nossos).

Os entrevistados ressaltam a formulação da PNAN, o fato de ter contemplado a questão do direito humano à alimentação - contribuição levada para o campo da SAN, e de ter sido alavancadora da necessidade da construção de relações intersetoriais pela área da saúde. Suas diretrizes destacam a necessidade do estímulo às ações intersetoriais que garantam o acesso universal aos alimentos 21 .

Assim, considerando esse resgate histórico, para que a PNAN consolide-se e o processo de integração intersetorial avance, torna-se importante, primeiramente, contar com a organização da atenção nutricional no âmbito do SUS. Nesse sentido, alguns avanços importantes foram obtidos no período em estudo:

“...o processo de ter criado o Fundo de Alimentação e Nutrição, de ter gerado, ainda que com muito pouco recurso, a possibilidade de financiar a gestão da política nos municípios de grande porte, além dos estados, que já era uma prática habitual, gerou uma mobilização enorme, um movimento impressionante. E são pouquíssimos recursos, mas geram uma organização, porque potencializam uma possibilidade de organizar esse desenho da alimentação e nutrição, da política no nível local" (Entrevistado no 07, governo, grifos nossos)

O entrevistado registra a realização do repasse de recursos com a institucionalização do Fundo de Alimentação e Nutrição (FAN) 23 e a sua importância estratégica para o fortalecimento da PNAN nos níveis estadual e municipal, processo que colaborou para a estruturação de uma rede nacional na área de alimentação e nutrição.

Em relação aos avanços naárea da saúde como contribuição específica para a construção da SAN, os entrevistados destacam algumas questões:

“...em termos de políticas públicas da saúde, a gente computou alguns avanços, por exemplo, no próprio desenho que foi dado para a área da Nutrição na atenção básica, com o NASF. É até um avanço tímido, mas entendo que como nutrição na atenção primária houve uma certa incorporação da SAN até nas atribuições do nutricionista. A questão da produção e consumo dos alimentos está na pauta do nutricionista do NASF, então eu acho que essa incorporação acontece. Um outro elemento de concretização disso foi o próprio PSE, que tem várias interfaces na promoção da saúde, e um campo muito forte que foi a promoção da alimentação saudável, e logo, com a incorporação dessa dimensão como atribuição da equipe de saúde da família na escola, incorporada pelo PSE. A alimentação saudável rapidamente se incorporou, procurou-se fazer um manual operacional conjunto, para profissionais de saúde e de educação, com uma temática e com abordagens da questão alimentação e nutrição que permitissem tanto ao profissional da saúde quanto ao da educação abordar o tema nas suas realidades..." (Entrevistado no 07, governo, grifos nossos).

O entrevistado faz uma importante referência à implantação dos Núcleos de Apoio à Saúde da Família (NASF) 24 na atenção básica como uma ação de promoção da abordagem da SAN, em função da inserção do nutricionista; ressalta ainda o interesse despertado na comunidade escolar sobre a alimentação saudável, com a implantação do Programa Saúde na Escola (PSE) 25, uma iniciativa dos ministérios da saúde e da educação.

No entanto, apesar do registro das contribuições significativas da PNAN para a construção da SAN, os entrevistados reconhecem as dificuldades apresentadas pela área de nutrição no âmbito do SUS:

“...eu não enxergo que a Nutrição está presente no discurso da integralidade que é feito pelos profissionais do SUS... Porque mesmo quando a gente fala da integralidade, do cuidado, as dimensões da Nutrição são muito pouco exploradas, os profissionais trabalham ainda com conceituações muito primárias da Nutrição, desconhecem a Nutrição, não são capazes de protagonizar informações consistentes para a população, de uma forma geral, no nível da atenção primária que é considerada a porta de entrada do sistema... Os profissionais não estão apropriados da dimensão da Nutrição, e aí eu estou falando de agentes comunitários, enfermeiros, médicos... Para resolver a integralidade, então a Nutrição vira uma palestra, uma ação educativa... (Entrevistado no 10, sociedade civil, grifos nossos).

O entrevistado destaca a importância crescente da integralidade da saúde no âmbito do SUS, mas registra que a situação vivenciada pela área de nutrição no sistema de saúde revela a 
falta de incorporação e de aplicação deste conceito essencial. Segundo a fala, a visão da nutrição por parte dos profissionais da saúde ainda é pontual e não consegue abarcar todas as suas dimensões tanto no âmbito do SUS quanto fora dele, que compreendem desde a assistência nutricional até as ações de promoção da alimentação saudável numa perspectiva ampla e intersetorial.

Seguem as reflexões de um entrevistado sobre os condicionantes dessa situação:

“...a nutrição é ainda vista na saúde de duas formas: ou ela é vista como só o campo da alimentação, como questões intersetoriais que estão fora da saúde... ou a questão da nutrição ser vista pela desnutrição. $E$ aí essa situação não caberia só ao setor saúde, porque você vai resolver a Nutrição dando comida, e dar comida não é uma função da saúde e... então pronto! E essas questões são colocadas assim...!" (Entrevistado no 10 , sociedade civil, grifos nossos).

Segundo o entrevistado, a compreensão predominante na área da saúde é de que a fome e a desnutrição se resolvem com a garantia do acesso ao alimento, e como o setor saúde não fornece o alimento esse assunto não pode ser solucionado no âmbito do SUS, não sendo responsabilidade de seus trabalhadores. Conforme o comentário, há uma certa "indiferença" em relação à necessidade da garantia do acesso à alimentação adequada enquanto direito, que é tratada no âmbito da SAN. Ainda não há uma abordagem adequada no âmbito do setor que considere a integração dos enfoques biológico e social na compreensão da determinação do estado nutricional da população ou de que tais desafios poderão ser vencidos mediante uma articulação intersetorial.

Para alguns dos entrevistados a atenção primária em saúde é a área que apresenta maior afinidade com as questões da SAN, mas mesmo neste âmbito do sistema há uma certa fragilidade institucional:

“...é a área que tem maior potencial de comunicação com a SAN, (...) e o quadro que a gente viu dos municípios, é um quadro muito preocupante, no sentido de como as poucas coisas que existem são absolutamente circunstanciais. Então a gente foi atrás de informações sobre quais os fatores que motivaram as ações que existem... As pessoas se baseiam em dados, elas usam indicadores? É raríssimo isso, a ação baseada em fatos, em evidências! As pessoas que são vinculadas à coordenação de alimentação e nutrição, muitas vezes não sabem de onde vem o recurso, de quanto é esse recurso, não sabem se a ação que elas desenvolveram gerou algum resultado, poucas pessoas conhecem a PNAN... Então ainda, você tem uma certa informalidade, não tem processos de política pública, programas públicos ainda muito bem estruturados" (Entrevistado no 10, sociedade civil, grifos nossos).

Os entrevistados também falam do papel ainda incipiente das Coordenações de Alimentação e Nutrição no nível municipal, um trabalho assumido por profissionais que atuam sozinhos, isolados e que muitas vezes não incorporam nas suas ações os conceitos do planejamento em saúde, da epidemiologia nutricional, as abordagens da nutrição em saúde coletiva e as diretrizes da PNAN. Tais situações impedem o fortalecimento da área de nutrição, gerando a ausência da atuação necessária e prejuízos para a saúde da população.

Tal problema poderia ser atribuído a uma insuficiente inserção do nutricionista no SUS, profissional que atua mais diretamente com o tema, seja na gestão ou na atenção primária 26 . Mas a problemática não se restringe somente a isso, pois também no âmbito da formação do nutricionista ainda persistem deficiências, especialmente em saúde coletiva, conforme segue:

“...estamos indo para as escolas de Nutrição para ver como o profissional é formado em saúde pública, que tipo de disciplina, o quanto essas disciplinas trabalham documentos e prioridades estratégicas do ministério e tal... Se a gente pega os estudantes, eles dizem que a saúde pública é uma coisa muito grande, muito geral, então você vai por aquela coisa desfocada, como se não tivesse método em saúde pública, como se não tivesse condições de se avaliar, de monitorar, de ver impacto e tal, e isso eu acho que você encontra de alguma maneira nas três esferas de governo, essa informalidade, essa improvisação! Historicamente, a situação melhorou sensivelmente, mas olhando para o futuro ainda precisa de um investimento em qualificação, em gestão, fazer um trabalho dentro da saúde pública que tenha esse espelho dentro da SAN, que tenha método, que tenha processo..." (Entrevistado no 10, sociedade civil, grifos nossos).

No entanto, apesar de todas as questões levantadas, aspectos mais estruturantes são delineados na busca de uma compreensão mais profunda sobre o porquê das limitações que interferem na institucionalização da nutrição no âmbito do SUS:

“...a priorização que a própria Saúde faz do tema é uma dificuldade, mas eu não vou colocar isso como defeito, porque a área da Saúde é muito complexa, ela tem uma pauta enorme, ela tem dificuldades de traçar prioridades, porque tudo é importante...! Porque tudo exige muitos recursos, muita mobilização, e é óbvio que a gente tem aí o ponto de vista dos grandes, do mercado da Saúde, da tecnologia da Saúde... e a gente está falando de alimentação, de nutrição, de 
coisas muito básicas, de processos que deveriam ser mais bem resolvidos na sociedade, que nem seriam questões fundamentais, mas não foram resolvidos e vão sempre exigir essa vigilância, esse cuidado, então acho que as dificuldades são essas e daí essa pauta não entra como prioridade, aí não entra orçamento, e aí você tem dificuldade de alavancar processos na sociedade, nos níveis de gestão e em toda a rede" (Entrevistado no 07, governo, grifos nossos).

A fala expressa uma percepção de que institucionalmente a área da saúde ainda apresenta dificuldades em priorizar a área de alimentação e nutrição. Tal situação tem relação com os desafios que a sociedade brasileira enfrenta historicamente em função da desigualdade social, que repercutem na alimentação e nutrição da população e que precisariam já ter sido vencidos. No entanto, reconhece as dificuldades inerentes ao processo de definição das prioridades no âmbito do SUS, em função da existência de múltiplas necessidades, ao mesmo tempo em que se refere à disputa pelo recurso disponível pelos diferentes setores da Saúde, sobretudo os de maior complexidade.

Os depoimentos a seguir aprofundam a discussão, explicitando a importância que a construção da SAN tem para a promoção da saúde, e os principais motivos que impedem a construção desta relação:

"É obviamente central porque se os alimentos são uma questão vital para a existência do ser humano, a produção da saúde das pessoas reflete diretamente o que elas comem, como elas comem... então, o reconhecimento da Alimentação e a sua contribuição para a produção da Saúde deveria ser algo mais óbvio do que é. O problema é que a questão esteja nem tanto nisso, mas na direção que tomou a formação médica e o negócio da saúde, a economia da saúde e é aí que eu acho que está a principal resistência, a principal dificuldade (...) acho que a economia tem uma forte entrada nessa explicação, porque é um círculo vicioso, eu acho até que é perverso... É um tipo de formação que reforça um tipo de tratamento, de atuação do serviço público que, por sua vez, legitima uma estrutura econômica forte... É um ciclo perverso... Eu acho que muito da explicação do papel secundário que a alimentação tem na saúde tem relação com esses interesses econômicos, que giram em torno de um dos setores mais lucrativos, porque incorporar os alimentos da maneira que a gente quer muda o foco, você vai ensinar as pessoas a ter uma vida mais saudável..." (Entrevistado no 02, sociedade civil, grifos nossos).

O entrevistado registra a importância dos alimentos e da alimentação para a saúde, e faz uma reflexão sobre como este direito fundamental passa a ser desconsiderado em função da medicalização da saúde, da influência das corporações e da geração de um mercado lucrativo baseado na doença, como processos antagônicos ao que é proposto pela área de alimentação e nutrição, sobretudo com base no enfoque da SAN e no direito humano à alimentação adequada e saudável.

\section{Discussão}

\section{Avanços e desafios identificados no processo histórico}

Os entrevistados fazem menção aos avanços da institucionalidade da PNAN nos estados e municípios, sobretudo após a criação do FAN, o que sem dúvida contribuiu para o aumento da capilaridade das ações da política no país.

Avaliações realizadas em seminários estaduais e nacional sobre os dez anos da PNAN também destacaram a importância dos avanços conquistados 27 . No entanto, registraram que após esse período de existência, a sua coordenação técnica ainda "ocupa um nível hierárquico restrito, gerando baixa autonomia e força política, fato que dificulta o diálogo intersetorial e as negociações externas" 27 (p. 9). O seminário nacional avaliou que tal situação reflete-se também nos estados e municípios, onde muitas vezes a atuação da área de Alimentação e Nutrição fica "centrada em uma pessoa, fato que limita a atuação técnica do profissional e a ação política que precisa ser feita no campo da alimentação e nutrição” 27 (p. 9). O mesmo documento registra que há uma "baixa inserção nos programas do SUS, o que se traduz pela insegurança do financiamento e pela ausência de organização administrativa que dê suporte dificultando a atuação das áreas" 27 (p. 9).

Os depoimentos também destacam dificuldades na gestão da área de alimentação e nutrição nos níveis estadual e municipal. A ausência de uma atuação mais qualificada impede o fortalecimento da área de Nutrição e assim compromete a saúde da população. Verifica-se portanto, que houve uma sintonia das conclusões obtidas no seminário nacional com as falas dos entrevistados.

A implantação dos NASF com a participação do nutricionista foi considerada como fundamental para o fortalecimento da nutrição no SUS ${ }^{28}$, processo que por sua vez é entendido como essencial para possibilitar o diálogo com o campo da SAN.

A atuação do nutricionista no SUS apresenta duas dimensões: uma que se refere ao processo 
da gestão das políticas e outra que diz respeito à dimensão da assistência, relacionada aos componentes da promoção, prevenção, proteção, diagnóstico, tratamento e reabilitação em saúde 28,29,30. Trata-se, portanto, do trabalhador da saúde que tem como missão essa atuação específica e também a de articular uma ação conjunta com os demais profissionais, gerando a corresponsabilização necessária pelo trabalho dessa temática no âmbito do SUS 31 .

A maior inserção de profissionais provenientes desse campo de conhecimento, que tem por objeto o estudo da ciência da nutrição, pode contribuir de fato no avanço do processo. Dentre as categorias que atuam na área da saúde, o nutricionista conta com uma formação técnica aprofundada na área de alimentação e nutrição 28,29 , podendo assim contribuir na identificação dos problemas existentes, bem como na resolutividade de uma série de demandas verificadas nos diferentes níveis de complexidade do SUS e que até o momento não são adequadas e suficientemente enfrentadas 28,30,31.

Apesar do avanço obtido com a criação dos NASF, que inclui o nutricionista em sua equipe, a inserção deste profissional no SUS ainda é insuficiente 28,29. O pequeno número de nutricionistas na atenção primária, assim como também na alta complexidade e na gestão 29,30, limita as ações na área de alimentação e nutrição no sistema de saúde e colabora no represamento das várias demandas existentes. Consiste, portanto, em uma violação do direito da população ao cuidado e à atenção nutricional.

No entanto, o problema não se restringe somente à questão mencionada, pois além do número reduzido no SUS, também no âmbito da formação dos nutricionistas ainda existem deficiências na incorporação dos conceitos e conteúdos da saúde coletiva que confeririam ao profissional maior condição de ter uma atuação mais resolutiva 30,32 . Apesar dos esforços realizados pela coordenação da PNAN em relação à formação de gestores para a área de alimentação e nutrição, e de um conjunto de universidades que tem procurado aperfeiçoar e adequar a formação dos nutricionistas na área da saúde coletiva 33 , ainda predomina o enfoque clínico 34 . Embora tal situação não seja exclusiva do nutricionista, pois ocorre na formação da maior parte das categorias profissionais que atuam na área da saúde 34,35, compromete a sua atuação e o próprio serviço de saúde.

Os entrevistados também trouxeram outras contribuições importantes, sobretudo no reconhecimento das dificuldades dos demais profissionais de saúde em trabalhar com a nutrição, em termos técnicos e em perspectiva crítica para uma atuação política pela promoção do direito à saúde, mediante a garantia do direito à atenção nutricional 30,31 .

A insuficiente inserção do nutricionista no SUS, assim como a dificuldade relativa à adequação da formação necessária na área de alimentação e nutrição por parte da equipe de saúde e dos gestores 30,35 , aliadas à fragilidade da institucionalidade da área sobretudo nos níveis estadual e municipal, contribuem para aumentar as dificuldades existentes no que se refere à consolidação do trabalho da área de nutrição no SUS. Tal aspecto gera uma visibilidade restrita da temática no âmbito da saúde, especialmente em relação à potencialidade do trabalho que necessitaria ser desenvolvido 36,37 .

Finalmente, os entrevistados buscaram identificar as razões mais profundas para tal situação, fazendo menção a um elemento estruturante dessa problemática: o predomínio, no país, do modelo biomédico, curativista, hospitalocêntrico, que carreia a maior parte dos recursos e dos esforços do SUS para a alta complexidade 2, situando a promoção da saúde e suas principais estratégias, e dentre elas as da alimentação e nutrição, ainda em uma posição secundária 1,2,36,37.

\section{Considerações finais}

A área da saúde está na gênese do movimento social que, com uma forte participação da sociedade civil, articulou a estruturação das políticas de SAN e do próprio SISAN no Brasil. A instituição da PNAN em 1999, tornou-a um marco para a SAN no Brasil por ter sido a única política pública que, na época, manteve essa temática na agenda de governo, sustentando a necessidade de o setor saúde buscar o estabelecimento da intersetorialidade para garantir o acesso da população à alimentação adequada e saudável. Da sua gênese até 2003, a PNAN passou por um processo de estruturação e a partir de 2006, com a instituição do SISAN, foram ampliadas as condições políticas para a sua alavancagem.

No entanto, apesar dos avanços significativos na construção de sua institucionalidade e das perspectivas positivas apresentadas, a análise sobre o período de 2003 a 2010 evidenciou a persistência de uma ainda insuficiente inserção da área de nutrição no âmbito do SUS, o que por sua vez compromete a articulação da saúde com a SAN.

Tal constatação deve ser analisada em profundidade, uma vez que o simples reconhecimento do papel vital da nutrição para a saúde não é suficiente para garantir a sua priorização no SUS. É preciso reconhecer que o campo científico de qualquer temática, assim como o seu 
respectivo campo de práticas, constitui-se em "um campo social como outro qualquer, com suas relações de força e monopólios, lutas e estratégias, interesses e lucros, onde todas estas variantes assumem formas específicas, constituindo um mundo à parte" 36 (p. 26). É necessário ainda considerar que o SUS é um projeto da sociedade brasileira ainda em implementação, e cujo avanço depende de difíceis disputas no campo políticoinstitucional e do reconhecimento por parte do Estado e da sociedade em geral dos direitos que garantam de forma efetiva e democrática a produção social da saúde, que passa pela produção, distribuição e consumo de uma alimentação adequada e saudável para todos.

\section{Colaboradores}

S. A. Rigon participou da concepção do projeto, realização das entrevistas, análise do material das entrevistas e sua interpretação, e redação do texto. S. T. Schmidt colaborou na análise do material das entrevistas e sua interpretação, redação e revisão crítica. C. M. Bógus contribuiu na concepção do projeto, análise do material das entrevistas e sua interpretação, redação e revisão crítica.
Concluindo, sabe-se que o processo de construção intersetorial de políticas públicas quase sempre enfrenta dificuldades de ordem política. Assim, apesar dos obstáculos identificados pelo estudo, torna-se estratégico o fortalecimento dos espaços institucionais que têm o potencial para promover a intersetorialidade, como as CAISAN e os CONSEA, instâncias do SISAN, assim como a Comissão Intersetorial de Alimentação e Nutrição (CIAN), vinculada ao Conselho Nacional de Saúde (CNS).

O espaço dos conselhos mencionados tornase especialmente promissor para assumir tal empreitada, em função da participação social, aspecto crucial para impulsionar a construção transversal das políticas em discussão.

\section{Agradecimentos}

À Capes pela concessão de Bolsa do Programa de Desenvolvimento de Estágio no Exterior (PDEE) como apoio à realização da tese de doutorado com base na qual foi possível elaborar este artigo. 


\section{Referências}

1. Junqueira LAP. Intersetorialidade, transetorialidade e redes sociais na saúde. Rev Adm Pública 2000; 34:35-61.

2. Paim J. Reforma sanitária brasileira: contribuição para a compreensão e crítica. Salvador: Edufba/ Rio de Janeiro: Editora Fiocruz; 2008.

3. Burlandy L. A construção da política de segurança alimentar e nutricional no Brasil: estratégias e desafios para a promoção da intersetorialidade no âmbito federal de governo. Ciênc Saúde Coletiva 2009; 14:851-60.

4. Burlandy L, Bocca C, Mattos RA. Mediações entre conceitos, conhecimento e políticas de alimentação, nutrição e segurança alimentar e nutricional. Rev Nutr 2012; 25:9-20.

5. Magalhães R. Avaliação de políticas e iniciativas públicas de segurança alimentar e nutricional: dilemas e perspectivas metodológicas. Ciênc Saúde Coletiva 2014; 19:1339-46.

6. Brasil. Lei no 11.346, de 15 de setembro de 2006, cria o Sistema Nacional de Segurança Alimentar e Nutricional - SISAN com vistas em assegurar o direito humano à alimentação adequada e dá outras providências. Diário Oficial da União 2006; 18 set.

7. Leão M, Maluf RS. A construção social de um sistema público de segurança alimentar e nutricional: a experiência brasileira. Brasília: Ação Brasileira pela Nutrição e Direitos Humanos; 2012.

8. Brasil. Decreto no 7.272, de 25 de agosto de 2010 . Regulamenta a Lei no 11.346, de 15 de setembro de 2006, que cria o Sistema Nacional de Segurança Alimentar e Nutricional - SISAN - com vistas a assegurar o direito humano à alimentação adequada, institui a Política Nacional de Segurança Alimentar e Nutricional - PNSAN, estabelece os parâmetros para a elaboração do Plano Nacional de Segurança Alimentar e Nutricional, e dá outras providências. Diário Oficial da União 2010; 25 ago.

9. Câmara Interministerial de Segurança Alimentar e Nutricional. Plano Nacional de Segurança Alimentar e Nutricional: 2012-2015. Brasília: Câmara Interministerial de Segurança Alimentar e Nutricional; 2011.

10. Conselho Nacional de Segurança Alimentar e Nutricional. A segurança alimentar e nutricional e o direito humano à alimentação adequada no Brasil: indicadores e monitoramento da Constituição de 1988 aos dias atuais. Brasília: Conselho Nacional de Segurança Alimentar e Nutricional; 2010.

11. Instituto Brasileiro de Geografia e Estatística. Suplemento da pesquisa nacional por amostra de domicílios: segurança alimentar e nutricional. Rio de Janeiro: Instituto Brasileiro de Geografia e Estatística; 2014.

12. Conselho Nacional de Segurança Alimentar e Nutricional. Princípios e diretrizes de uma política de segurança alimentar e nutricional. Brasília: Conselho Nacional de Segurança Alimentar e Nutricional; 2004.

13. Costa CA, Bógus CM. Significados e apropriações da noção de segurança alimentar e nutricional pelo segmento da sociedade civil do Conselho Nacional de Segurança Alimentar e Nutricional. Saúde Soc $2012 ; 21: 103-14$.
14. Ferreira VA, Magalhães R. Nutrição e promoção da saúde: perspectivas atuais. Cad Saúde Pública 2007; 23:1674-81.

15. Recine E, Vasconcelos AB. Políticas nacionais e o campo da alimentação e nutrição em saúde coletiva: cenário atual. Ciênc Saúde Coletiva 2011; 16:73-9.

16. Spink MJ, Menegon VM. A pesquisa como prática discursiva: superando os horrores metodológicos. In: Spink MJ, organizador. Práticas discursivas e produção de sentidos no cotidiano: aproximações teóricas e metodológicas. São Paulo: Cortez Editora; 1999. p. 63-92.

17. Victora CG, Kanuth DR, Hassen MNA. Pesquisa qualitativa em saúde: uma introdução ao tema. Porto Alegre: Tomo Editorial; 2000.

18. Minayo MCS. O desafio do conhecimento: pesquisa qualitativa em saúde. 8a Ed. São Paulo: Editora Hucitec/Rio de Janeiro: ABRASCO; 2014

19. Bardin L. Análise de conteúdo. 4a Ed. Lisboa: Edições 70; 2009.

20. Rigon SA. A construção de políticas públicas promotoras de saúde: um estudo de caso sobre a Polí tica de Segurança Alimentar e Nutricional do Paraná [Tese de Doutorado]. São Paulo: Universidade de São Paulo; 2012.

21. Secretaria de Vigilância em Saúde, Ministério da Saúde. Política Nacional de Alimentação e Nutrição. Brasília: Ministério da Saúde; 2000.

22. Arruda BKG, Arruda IKG. Políticas de alimentação e nutrição no Brasil: breve enfoque dos delineamentos conceituais e propositivos. In: Taddei JAAC, Lang RMF, Longo-Silva G, Toloni MHA, organizadores. Nutrição em saúde pública. Rio de Janeiro: Editora Rubio; 2011. p. 397-422.

23. Ministério da Saúde. Portaria MS no 1.630, de 24 de junho de 2010, estabelece o repasse anual fundo a fundo para a estruturação e implementação das ações de alimentação e nutrição no âmbito das secretarias municipais e estaduais de saúde com base na Política Nacional de Alimentação e Nutrição. Diário Oficial da União 2010; 25 jun.

24. Ministério da Saúde. Portaria MS no 154, de 24 de janeiro de 2008, cria os Núcleos de Apoio à Saúde da Família (NASF). Diário Oficial da União 2008; 4 mar.

25. Casa Civil. Portaria CC no 6.286, de 5 de dezembro de 2007, institui o Programa Saúde na Escola (PSE) e dá outras providências. Diário Oficial da União 2007; $6 \mathrm{dez}$.

26. Lang RMF, Ribas MTGO. O nutricionista e as ações de nutrição em saúde. In: Taddei JAAC, Lang RMF, Longo-Silva G, Toloni MHA, organizadores. Nutrição em saúde pública. Rio de Janeiro: Editora Rubio; 2011. p. 437-53.

27. Comissão de Alimentação e Nutrição, Conselho Nacional de Saúde, Coordenação Geral da Política de Alimentação e Nutrição, Ministério da Saúde. Relatório final do Seminário Nacional de Alimentação e Nutrição no SUS - PNAN 10 Anos. Brasília: Ministério da Saúde; 2010. 
28. Geus LMM, Maciel CS, Burda ICA, Daros SJ, Batistel S, Martins TCA, et al. A importância da inserção do nutricionista na saúde da família. Ciênc Saúde Coletiva 2011; 16:797-804.

29. Vasconcelos FAG. A inserção do nutricionista no Sistema Único de Saúde. In: Taddei JAAC, Lang RMF, Longo-Silva G, Toloni MHA, organizadores. Nutrição em saúde pública. Rio de Janeiro: Editora Rubio; 2011. p. 423-35.

30. Boog MCF. Atuação do nutricionista em saúde pública na promoção da alimentação saudável. Revista Ciência \& Saúde 2008; 1:33-42.

31. Junqueira TO, Cotta RMM. Matriz de ações de alimentação e nutrição na atenção básica de Saúde: referencial para a formação do nutricionista no contexto da educação por competências. Ciênc Saúde Coletiva 2014; 19:1459-74.

32. Pádua JG, Boog MCF. Avaliação da inserção do nutricionista na Rede Básica de Saúde dos municípios da Região Metropolitana de Campinas. Rev Nutr 2006; 19:413-24.

\begin{abstract}
This article discusses the establishment of inter-sector action between health and food and nutritional security in Brazil from 2003 to 2010, when this issue was launched as a priority on the government's agenda. A qualitative study was developed according to constructivist epistemology, using key-informant interviews in the field's nationwide social oversight body. Advances and challenges in this process are addressed as analytical categories. The National Food and Nutrition Policy (PNAN) was mentioned as the link between the two fields, decentralized through a network with activity in the states and municipalities. However, the study found political, institutional, and operational obstacles to the effective implementation of the PNAN in the Brazilian Unified National Health System and consequently to a contribution to the advancement of Health and Food and Nutritional Security in the country. The predominance of the biomedical, curative, and high-complexity model was cited as the principal impediment, while health promotion policies like the PNAN were assigned secondary priority.
\end{abstract}

Food and Nutrition Security; Public Policies; Public Health Nutrition; Feeding
33. Coordenação de Alimentação e Nutrição, Departamento de Atenção Básica, Secretaria de Atenção à Saúde, Ministério da Saúde. Relatório de gestão 2007-2010. Brasília: Ministério da Saúde; 2011.

34. Amorim STP, Moreira H, Carraro TE. A formação de pediatras e nutricionistas: a dimensão humana. Rev Nutr 2001; 14:111-8.

35. Ceccim RB, Feurwerker LCM. Mudança na graduação das profissões de saúde sob o eixo da integralidade. Cad Saúde Pública 2004; 20:1400-10.

36. Almeida Filho N. Intersetorialidade, transdisciplinaridade e saúde coletiva: atualizando um debate em aberto. Rev Adm Pública 2000; 34:11-34.

37. Azevedo E, Pelicioni MCF, Westphal MF. Práticas intersetoriais nas políticas públicas de promoção da saúde. Physis (Rio J.) 2012; 22:1333-56.

\section{Resumen}

Se discute la construcción de la intersectorialidad entre el campo de la salud y el de la seguridad alimentaria y nutricional en Brasil, entre 2003 y 2010, período que inaugura la priorización de este tema en la agenda gubernamental. Para tal efecto, se desarrolló una investigación cualitativa, según la epistemología construccionista, mediante entrevistas con informantes-clave del órgano de control social en el campo de la seguridad alimentaria y nutricional dentro de una dimensión nacional. Los avances y desafíos del proceso se abordan por categorías de análisis. La Política Nacional de Alimentación y Nutrición (PNAN) se mencionó como articuladora entre los dos campos, siendo descentralizada por una red con actuación en los estados y municipios. Sin embargo, se registraron dificultades politicas, institucionales y operacionales para que la PNAN pudiera ser efectiva en el Sistema Único de Salud, y así contribuir al avance de la seguridad alimentaria y nutricional en el país. El predominio del modelo biomédico, curativo y de alta complejidad fue mencionado como el principal impeditivo, otorgando incluso a las políticas de promoción de la salud, como la PNAN, una posición secundaria en términos de su priorización.

Seguridad Alimentaria y Nutricional; Políticas

Públicas; Nutrición em Salud Pública; Alimentación
Recebido em 01/Nov/2014

Versão final reapresentada em 18/Ago/2015

Aprovado em 27/Ago/2015 